\title{
Passive Trust or Active Application: Changes in the Management of Difficult Childbirth and the Edinburgh Royal Maternity Hospital, 1850-1890
}

\author{
ALISON NUTTALL*
}

\begin{abstract}
Introduction
The history of the medical and nursing care given to parturient women has been approached in a number of ways. Early studies largely equated it with the development of obstetric technology that occurred from the early eighteenth century onwards, focusing on its potential to save maternal and foetal life, but without examining closely the frequency and significance of its actual use. ${ }^{1}$ Thereafter, feminist historians re-interpreted similar evidence to stress what they regarded as the degrading and invasive aspects of such technology, especially as it related to the increasing use of chloroform anaesthesia in the latter half of the nineteenth century. ${ }^{2}$ Interest then moved from the technology itself, to its effects on other aspects of care in childbirth, particularly on the eighteenth-century decline of the traditional midwife and the concomitant rise of the man-midwife. ${ }^{3}$

The above historiography implied that once forceps were publicly known, they were consistently and widely used. However, this has since been questioned. The use of detailed analysis of the casebooks and published writings of a number of men-midwives, in addition to contemporary printed debates between doctors and midwives, has produced a more complex and nuanced picture of the early use of forceps and related instruments. In this interpretation, it is argued that the use of instruments to deliver a live child initially played a crucial part in the conversion of male obstetric surgeons from attendants called only to deliver a dead child piecemeal, to men-midwives. Despite this, the use of instruments
\end{abstract}

\section{(C) Alison Nuttall 2006}

* Alison Nuttall, BA (Hons), MSc, PhD, RGN, SCM, School of History and Classics, University of Edinburgh, William Robertson Building, 50 George Square, Edinburgh, EH8 9JY, UK.

The author would like to thank the Wellcome Trust for their generous support; Dr Michael Barfoot for his invaluable archival advice and knowledge; Professor Roger Davidson for his patient guidance; the staffs of the Lothian Health Services Archive and Edinburgh University Special Collections for all their assistance; and the Wellcome Regional Forum, 2001, to whom this article was presented in a very early form, for their helpful comments.

${ }^{1}$ J M Munro Kerr, R W Johnstone and Miles H Phillips (eds), Historical review of British obstetrics and gynaecology, 1800-1950, Edinburgh, E \& S Livingstone, 1954, pp. 3-40, 71-84; Walter Radcliffe, Milestones in midwifery, Bristol, John Wright \& Sons, 1967.

${ }^{2}$ See, for example, Jenny Carter and Thérèse Duriez, With child: birth through the ages, Edinburgh, Mainstream, 1986, p. 117; Lois N Magner, A history of medicine, New York, M Dekker, 1992, pp. 273-5.

${ }^{3}$ See Jean Donnison, Midwives and medical men, 2nd ed., New Barnet, Historical Publications, 1988, especially pp. 42-44. However, midwives were not necessarily excluded from using instruments, and their use of them has been used to indicate their rising or falling status. See Christina Romlid, 'Swedish midwives and their instruments in the eighteenth and nineteenth centuries', in Hilary Marland and Anne Marie Rafferty (eds), Midwives, society, and childbirth, London, Routledge, 1997, pp. 38-60. 


\section{Alison Nuttall}

declined in the later eighteenth century, as a result of both their technical limitations, and a growing respect for and knowledge of the natural processes of birth among accoucheurs. The implication is that this decline was sustained. However, this analysis of principally eighteenth-century experience forms part of a general argument about the rise of menmidwives, and does not engage with the actual use of instruments by doctors thereafter. ${ }^{4}$

Patients' attitudes to increased medical involvement in childbirth have also been examined in both Britain and America through the medium of diaries and letters, although this has presented problems of class bias. These studies have shown that, supported by their family and female friends, maternity patients took both a robust approach to birth, and a cynical view of their medical attendants, with the implication that medical dominance in the delivery room developed only slowly. ${ }^{5}$ Studies based on nineteenth-century hospital and dispensary records have shown similar attitudes among the urban poor of both New York and Melbourne, emphasizing that even when such people used and benefited from medical provision they remained independent and suspicious of new and alien forms of care. ${ }^{6}$

The development of institution-based maternity care has also been studied. Drawing on debates about the rise of the man-midwife, initial focus was on the professional benefits to male practitioners of the new maternity hospitals established in the eighteenth century. It has been suggested that they profited professionally from a hospital hierarchy which placed them above female midwives on its staff, and therefore above all midwives in the perception of the public $;^{7}$ and also financially from their practice in the "public space" of the hospital, which allowed their work to be monitored by prospective private patients. ${ }^{8}$ However, nineteenth-century maternity hospital records in Scotland have not been subject to an intense examination of patients' treatment and response, and the medical care given by individual maternity institutions has not been studied in depth.

\footnotetext{
${ }^{4}$ Adrian Wilson, The making of man-midwifery: childbirth in England, 1660-1770, London, UCL Press, 1995.

${ }^{5}$ Judith Walzer Leavitt, Brought to bed: child-bearing in America, 1750-1950, New York, Oxford University Press, 1986, pp. 44-60; Patricia Jalland, Women, marriage and politics, 1860-1914, Oxford, Clarendon Press, 1986, pt. 2, pp. 131-85. See also Judith Schneid Lewis, In the family way: childbearing in the British aristocracy, 1760-1860, New Jersey, Rutgers University Press, 1986, for a similar approach to birth and medical men amongst the aristocracy.

${ }^{6}$ Virginia A M Quiroga, Poor mothers and babies: a social history of childbirth and child care institutions in nineteenth century New York City, New York and London, Garland Press, 1989; Nancy Schrom Dye, 'Modern obstetrics and working-class women: the New York Midwifery Dispensary, 1890-1920', J. Soc. Hist., 1987, 20: 549-64; Janet McCalman, Sex and suffering women's health and a women's hospital: The Royal Women's Hospital, Melbourne 1856-1996, Carlton, Melbourne University Press, 1998. Recent studies of
}

early twentieth-century maternity institutions in the East End of London have taken a more medically-focused stance, and instead emphasized the local community's affection for care-givers, by looking at the benefits to it of the medical and social care provided, particularly through the London Hospital and its dispensaries. (Lara Marks, 'Mothers, babies and hospitals: "The London" and the provision of maternity care in East London, 1870-1939', in Valerie Fildes, Lara Marks and Hilary Marland (eds), Women and children first: international maternal and infant welfare 1870-1945, London and New York, Routledge, 1992, pp. 48-73; idem, Model mothers: Jewish mothers and maternity provision in East London, 1870-1939, Oxford, Clarendon Press, 1994.)

${ }^{7}$ Margaret Connor Versluysen, 'Midwives, medical men and "poor women labouring of child": lying-in hospitals in eighteenth-century London', in Helen Roberts (ed.), Women, health and reproduction, London, Routledge \& Kegan Paul, 1981, pp. 18-49.

${ }^{8}$ Bronwyn Croxson, 'The foundation and evolution of the Middlesex Hospital's lying-in service, 1745-1786', Soc. Hist. Med., 2001, 14 (1): 27-57. 
The aim of this paper is to use detailed analysis of actual cases at the Edinburgh Royal Maternity Hospital [ERMH] to address the various issues raised by the above historiography: in particular, the place of (mainly instrumental) intervention at delivery in the nineteenth century, the development of institutional maternity care, and patients' attitudes to increasing medical involvement in birth. Thus the intention is primarily to interrogate the evidence of treatment from the records of a major Scottish maternity institution to show broader trends in the management of prolonged labour in the mid- to late nineteenthcentury, and the significance of these both for childbirth in general, and for the hospital in question. Whereas, in 1870, W John Kennedy, then house surgeon to the ERMH, could describe the management of difficult labour as a process of "trusting ... to the strength the pains had assumed", only twenty years later, his successor in post could describe the practice of himself and his superiors as being to "apply forceps \& deliver ... the child alive". ${ }^{9}$ It is this dramatic change from medical passivity to action that this article seeks to address.

In the first section, the principal source, the ERMH casebooks, are critiqued, and their importance for such a study established. After a general overview of the hospital from 1850 to 1912 to put the study in context, specific attention is paid to the relationship between the writing and lectures on the management of prolonged labour of Professor James Young Simpson, and the actual treatment offered at the ERMH in 1850 and 1870 . Thereafter, changes in maternity care described in the medical press in the later nineteenth century are set against the teaching and practice of Professor Alexander Russell Simpson. Shifts in ideology evident in his teaching and practice are related to the treatment given by the hospital. Finally, the significance of these changes, not only for the management of childbirth, but for the historiography of maternity care, is explored.

\section{The Indoor and Outdoor Delivery Casebooks of the ERMH: Their Nature and Purpose}

The principal sources for this paper are the Indoor and Outdoor Casebooks of the ERMH, supplemented, when available, by the Special and Ordinary Casebooks, in which only cases considered of exceptional interest were recorded. Maintenance of "an accurate register both of the In and Out-cases" was the house surgeons' responsibility. ${ }^{10}$ Some were more assiduous than others, and, particularly in the late 1850 s and 1860s, there are gaps in the records. Until mid-1878, medical students entered their own Outdoor cases into the appropriate ledger, leading to a variety of scripts and short asides. Taking the form of a double-page, single-line entry, both books had the potential to record the names, ages and parity of all patients, with the date of their delivery and the classification of their labour. In addition, the position and presentation of the child, and its state on

\footnotetext{
${ }^{9}$ Lothian Health Services Archive, Edinburgh University Library (hereafter LHSA), 1870 ERMH Special and Ordinary Casebook (hereafter SOCB) [LHB3/17/1], p. 38; 1890 ERMH Outdoor Casebook (hereafter OCB) [LHB3/18/5],
}

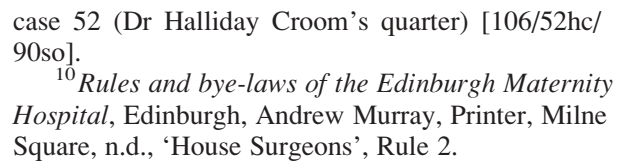




\section{Alison Nuttall}

delivery and at discharge, could also be recorded, along with the condition of the mother on discharge, and any other pertinent remarks. Exceptionally, and unlike many other surviving hospital casebooks, the name of the person responsible for the delivery was routinely given, and often those of others present. This makes it possible to examine the status of attendants. In addition, the Outdoor books included the patient's address, whilst in the Indoor books spaces for the "last catamenia", quickening, the lengths of the stages of labour, the weights of the child and placenta, and the lengths of child and umbilical cord, were also provided.

The column headings indicate that the books were not intended primarily to be records of treatment, but to provide regular, relevant observations on an individual's labour and its outcome. James Simpson, the Professor of Midwifery in Edinburgh, ${ }^{11}$ hoped to improve the management of labour through scrupulous measurement and evaluation, for which such casebooks provided the raw data, and in 1848 he published two papers stressing the importance of medical statistics in assessing treatment. ${ }^{12}$ Thus, the individual's record was principally part of a greater series of observations, and no specific site for recording their personal treatment was provided. However, this did not deter the record-keepers, who clearly felt such details should be included: they regularly annotated the classifications of labour, and made frequent use of the "Remarks" column to include a large number of case summaries and comments, thereby making a major contribution to the overall historical value of the casebooks.

As sources, the casebooks present problems in terms of their legibility, and in the sheer quantity of cases recorded, as well as in obtaining independent corroboration. In addition to this, the records are often incomplete, but inconsistently so. In the years examined, this is most noticeable in the 1870 Outdoor cases, in almost 10 per cent of which no record was made of whether or not the child was born alive. Despite these difficulties, the clinical records of the ERMH are a major historical source for the development of maternity care in late-nineteenth- and early-twentieth-century Britain. By recording daily activity, they offer the opportunity to examine the practice of the hospital, both Indoors and Out, and therefore the degree to which the new treatments of the nineteenth century were actually used. They illustrate what doctors did in reality, rather than what they wrote or advocated, providing evidence of the interaction between patients, their relations, and their doctors. ${ }^{13}$

This paper is based on material taken from a study of all the cases recorded by the ERMH in four calendar years, approximately twenty years apart (1850, 1870, 1890, and 1912). These were collected and analysed to provide a study of medical practice and treatment, and staff and patient experience at the hospital and in its Outdoor service, over its first

\footnotetext{
${ }^{11}$ Sir James Young Simpson Bt (1811-1870), Professor of Midwifery and the Diseases of Women and Children at the University of Edinburgh, 1839-70.

${ }^{12}$ James Y Simpson, Some remarks on the value and necessity of the numerical or statistical method of inquiry as applied to various questions in operative surgery, Edinburgh, Sutherland and Knox, 1848; and Report of the Edinburgh Royal Maternity Hospital from 1844 to 1846, Edinburgh, Sutherland and Knox,
}

1848, reprinted from Monthly Journal of Medical Science, Nov. 1848. However, much of the later ERMH material appears not to have been used at the time of its creation.

${ }^{13}$ For further discussion of this, see Guenter B Risse and John Harley Warner, 'Reconstructing clinical activities: patient records in medical history', Soc. Hist. Med., 1992, 5 (2): 183-205. 
seventy years. Additionally, the medical records of Indoor patients were linked by name to their social details, as recorded in the hospital Births Registers. ${ }^{14}$

\section{The Edinburgh Royal Maternity Hospital: An Overview}

The ERMH was founded as a maternity charity in 1844, to provide lying-in care for both Indoor and Outdoor patients, and to fill the educational and social gap left by the Edinburgh General Lying-in Hospital [EGLIH]. This had been owned by James Hamilton, the previous Professor of Midwifery, and sold after his death in settlement of his estate. The new hospital described itself as a charity and gave precedence to its ordinary directors over the Medical Board, but it was very much the heir of its predecessor, not least in educational function. Like the EGLIH, it was committed to providing practical midwifery experience to fee-paying male and female pupils, and it was dependent on the income they yielded. Further, the incumbent professor of midwifery continued to be associated with it as one of the ordinary medical officers, and it was the beneficiary of financial gifts and loans from him. ${ }^{15}$

Over its first thirty-five years the ERMH occupied six sites, which, combined with its persistent financial problems, suggests its survival was marginal. However, in 1879, it made its final move for sixty years to the custom-built maternity hospital at 79 Lauriston Place, funded by money "collected to perpetuate the memory of Sir James Simpson". ${ }^{16}$ Throughout much of the nineteenth century, the hospital suffered from lack of widespread public support: even in 1895 Dr John Moir could speak of the continuing existence of "a good deal of feeling against supporting the Maternity Hospital". ${ }^{17}$ This prejudice seems to have had its roots in a fear, probably arising from the very high proportion of single inmates, that supporting the hospital was in some way sponsoring immorality. Evidence of this fear can be found in the Ladies' Committee's suggestion that "girls from houses of a disreputable character" should no longer be admitted. ${ }^{18}$

Thus, although it was also partly funded by subscription, the educational fees paid by house surgeons, medical students and female pupils were a necessary part of its income. The requirement for patients to have a subscriber's ticket before admission was dropped in 1870 , in favour of open access for women in need, and from this time the managers made half-hearted attempts to emphasize the hospital's medical function, and its provision of midwifery training. None the less, the fund-raising for the Married Women's Pavilion (opened in 1895) stressed the Outdoor services it provided rather than those given Indoors. As late as 1901, the managers regretted the rising mortality rate that accompanied an increasing number of cases admitted "after outside endeavour has failed", 19 apparently

\footnotetext{
${ }^{14}$ This analysis forms the basis of the author's thesis: 'The Edinburgh Royal Maternity Hospital and the medicalisation of childbirth in Edinburgh, 1844-1914: a casebook-centred perspective' (PhD thesis, University of Edinburgh, 2003).

${ }^{15}$ In 1856 Simpson lent money to the directors to enable them to purchase Chapel House. (LHSA, ERMH Directors' Minutes (hereafter DMERMH) [LHB3/1/2], 2 May 1856). Later fund- and status-raising efforts emphasized the link between the two hospitals.
}

\footnotetext{
${ }^{16}$ A R Simpson, 'Sketch of the history of the Royal Maternity and Simpson Memorial Hospital', in G A Gibson, C W Cathcart, and D Berry Hart (eds), Edinburgh Hospital Reports, vol. 1, Edinburgh and Leeds, Young J Pentland, 1893, pp. 46-7.

${ }^{17}$ LHSA, DMERMH [LHB3/1/4], 26 Sept. 1895.

${ }^{18}$ LHSA DMERMH [LHB3/1/3], 8 Dec. 1876. The suggestion was rejected.

${ }^{19}$ LHSA, ERMH Annual Report (hereafter ARERMH) [LHB3/7/57], 1901.
} 


\section{Alison Nuttall}

uncertain whether the purpose of the hospital was to provide expert care in obstetric emergencies, or shelter to the destitute pregnant. Anxieties about the attitude of both patients and public towards the ERMH were still evident in $1913 .^{20}$

Although a nurse was employed intermittently in the 1850s, until 1881 the only permanent salaried member of staff was the matron. Her principal role was housekeeping and administration, but most matrons also had midwifery experience. In 1881, the additional permanent post of Staff Nurse was created in response to medical anxieties about the complete turnover of all female pupils and house surgeons every three months, and the need to educate the new intake quickly in antiseptic techniques. The matron also oversaw the nurses' Outdoor work, but when the Leith Branch opened, a further midwifery sister was appointed to run it. Additional sisters were gradually added to the hospital staff in the early twentieth century, and from 1909 the senior house surgeon was rewarded with a weekly honorarium during his second three months at the hospital. ${ }^{21}$ Otherwise, until after the First World War, the hospital was completely dependent upon the labour of its feepaying trainees, and upon the voluntary work of its senior doctors.

For the first twenty-seven years of the hospital, the senior doctors attended when they were called. However, in 1871 it was decided to divide the hospital year into quarters, each under the supervision of one ordinary physician. ${ }^{22}$ The professor invariably took the November-January slot, his annual university lecture course running daily from late October to the end of March. In 1884, two honorary assistant physicians (placed between the ordinary physicians and the house surgeons in the hospital hierarchy) were introduced to supplement the medical staff. They were intended to provide extra Outdoor supervision for the rapidly growing number of medical students associated with the hospital. From the late-1870s, all the senior doctors closely associated with the hospital lectured regularly in the city's medical schools.

In the early years, the ERMH provided inpatient care for only twenty-four patients at a time, and, although this number did rise, before 1914 only approximately one-third of its patients were delivered Indoors. Socially, the Indoor patients were a distinct group from those delivered in their own homes. Before 1912, the majority were unmarried, whilst the rest were typically born outside Edinburgh, had little family support, and were either temporarily or permanently abandoned by their husbands. ${ }^{23}$ Only a very small group of inpatients can be identified as apparently admitted for obstetric reasons in each year studied before 1912. This primarily social function of the hospital was recognized by its staff: in 1881 John Halliday Croom wrote that "the great majority of cases ... come voluntarily ... simply for shelter till the confinement is over". ${ }^{24}$ This can also be demonstrated by the recorded classification of their labours. In both 1850 and 1870,79 per cent of

\footnotetext{
${ }^{20}$ LHSA, ARERMH [LHB3/7/68, 69], 1912, 1913; DMERMH [LHB3/1/5], Memorandum for the National Insurance Commissioners, 29 Nov. 1912; ERMH Medical Board Minutes (hereafter MBMERMH) [LHB3/2/1], 24 Sept. 1913.

${ }^{21}$ LHSA, MBMERMH [LHB3/2/1], 15 Jan. 1909.

${ }^{22}$ LHSA, MBMERMH [LHB3/2/1], 1 Nov. 1871.

${ }^{23}$ For example, David Stevenson, coachman, lived in Melrose, whilst his wife, from Stranraer, gave her
}

address as 21, Queen Street (LHSA, 1850 ERMH Indoor Casebook (hereafter ICB) [LHB3/16/A], case 2007 [042/2007/50fi]); Sarah Jameson, whose husband William Hutchinson, a joiner, was "at sea", was born in Jamaica (LHSA, 1850 ICB [LHB3/16/A], case 2164 [074/2164/50si]).

${ }^{24}$ J Halliday Croom, 'The systematic use of antiseptics in midwifery practice', Edinburgh med. $J$., 1881, 26, no. 8, pt 2: 712-21, p. 714. 
labours were clearly classified as "normal" without qualification, whilst only 1 to 2 per cent were considered "complex", when there were medical problems with either mother or baby. By 1890 complex cases had risen, but only to 5 per cent.

The reluctance to be admitted shown by the Outdoor patients in the three earlier cohorts confirms this picture of the ERMH as principally a social shelter, possibly justifying Dr Charles Bell's description of it as a "lodging house for women of an improper character". ${ }^{25}$ In 1870, the doctors attending Williamina Bayne felt she should be transferred to the hospital prior to delivery. However, her relations disagreed and "a good deal of talking [was] got through" 26 before they finally consented. In 1890, Mrs Moffat suffered uterine rupture at home, but when the doctors " $[\mathrm{t}]$ ried ... to get her removal to hospital ... neither she nor her relatives would allow it". ${ }^{27}$ As a further illustration of this reluctance, in 1890 the number of major operations Outdoors exceeded the number Indoors.

However, by 1912 the inpatient profile had changed. The percentage of recorded married patients now slightly exceeded that of single girls, whilst the percentage of normal deliveries had fallen to 63 per cent. Complex cases had risen to 14 per cent. The number of married women with no recorded Edinburgh connection at the ERMH had greatly increased, from six in 1890 (of whom only two had obstetric problems), to forty-five in 1912, of whom only five had no recorded problems. The intervention rate among the forty-five was 71 per cent, compared with 18 per cent for all inpatients in that year. Chloroform was used in 29 per cent of their cases, compared with 5.5 per cent in the case of other inmates, and less than 2 per cent Outdoors. Clearly, these were women who had travelled to Edinburgh to access the obstetric expertise of the ERMH staff.

The attitudes of Outdoor patients had also changed by 1912. Unlike 1890, no major interventions took place in patients' homes. In contrast to the fatal experience of Mrs Crerar, who in 1890 had suffered uterine rupture as a result of a crossbirth, "Dr Bloom ... was called down to Leith with the message that there was a 'breech presentation' \& that pat[ient] was making no progress. On arrival a shoulder position was diagnosed \& ... the case was sent up to the R.M.H." where she was safely delivered of a stillborn child. ${ }^{28}$ ERMH patients now accepted that emergency admission was sometimes necessary.

Thus the patient records of the ERMH indicate that it was only between 1890 and 1912 that the hospital ceased to be primarily a social shelter, and began to be perceived by the public as principally giving care to the obstetric sick. However, there had already been a major change in the institution's management of prolonged labour. Between 1870 and 1890 intervention in singleton deliveries in the care of the hospital increased fourfold, from 2 to 9 per cent. This change was more striking among Indoor patients, rising from approximately 4 to 19 per cent, but it took place in both departments, Outdoor interventions increasing from approximately 1 per cent in 1870 to approximately 5 per cent in 1890 (see Figure 1). The unaltered attitudes of both Indoor and Outdoor patients to the hospital over this period indicate that this was genuinely the result of a change in medical thinking, rather

\footnotetext{
${ }^{25}$ LHSA, DMERMH [LHB3/1/2], 3 July 1871.

${ }^{26}$ LHSA, 1870 SOCB [LHB3/17/1], p. 40.

${ }^{27}$ LHSA, 1890 OCB [LHB3/18/5], case 34 (Dr Underhill's quarter) [255/34u/90fo]; 1890 SOCB [LHB3/17/6], p. 76.
}

\footnotetext{
${ }^{28}$ LHSA, 1912 Students' External Casebook (Leith Branch) [LHB3/18/29], case 22 [22/22/1912/Leith]; 1912 SOCB [LHB3/17/13], pp. 6-7; 1912 ICB [LHB3/ 16/3], case 74 (Dr Haultain's quarter) [74/074/hault/ 1912i].
} 
Alison Nuttall

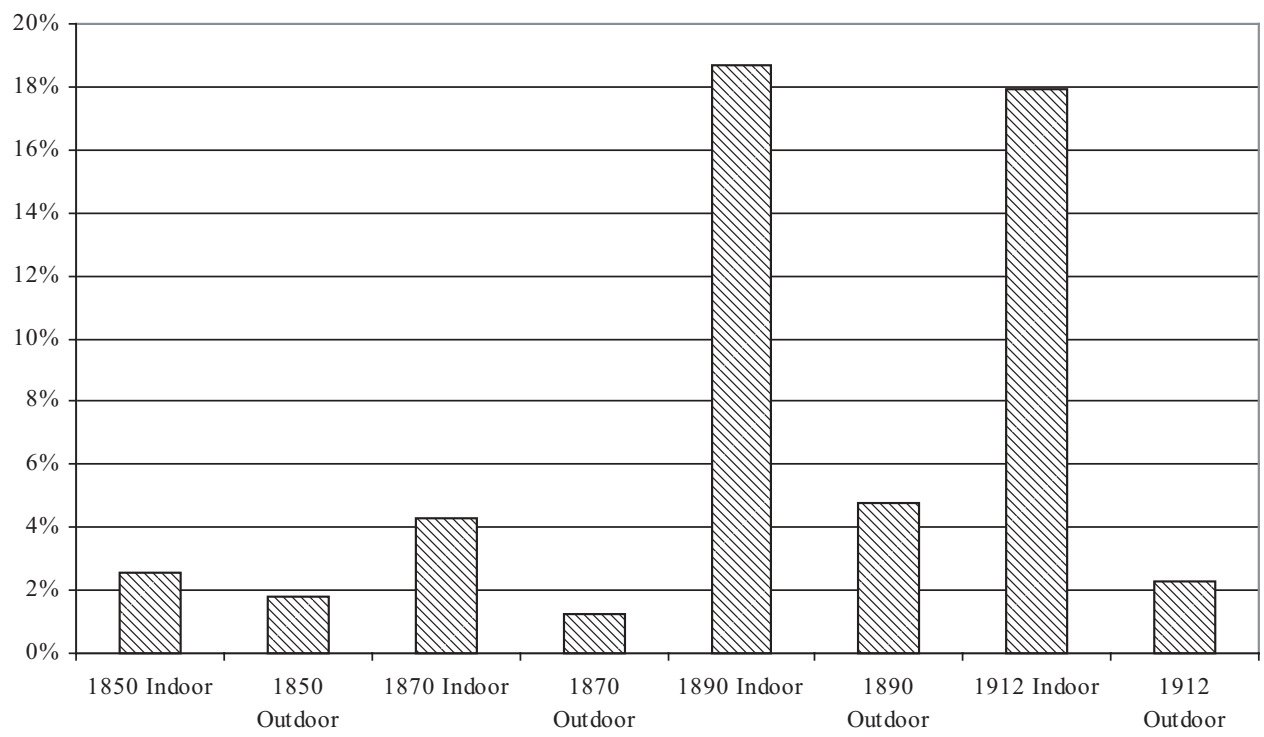

Figure 1: Interventions at delivery at the ERMH, 1850-1912

Source: ERMH Indoor and Outdoor casebooks for 1850, 1870, 1890 and 1912.

than of any increase in "problem patients". The following section will examine the background to the change in two ways, firstly by exploring the theory of the management of labour which informed the training of staff at the ERMH, pre-eminently articulated through the lectures and writings of James Young Simpson, and secondly by using patient records to examine actual practice.

\section{Professor James Young Simpson and the Management of Prolonged Labour at the ERMH, 1850-70}

Through both his teaching and his personality, Simpson was extremely influential in midwifery during this period. Indeed, in many ways he regarded midwifery and obstetrics as of greater value to society than medicine and surgery. ${ }^{29}$ He was appointed Professor of Midwifery in 1839, and gave a course of 100 lectures on his subject annually until his death in May 1870. Two manuscript sets of notes from this course, taken in 1850-1 and 1862-3, and a set published posthumously but presumably related to his course as given in either 1868-9 or 1869-70, are used here to give insight into his views on the management of labour as he wished them to be understood by his students. ${ }^{30}$ In addition, he also published

${ }^{29}$ LHSA, 'Heads of lectures on midwifery etc. Delivered by J. Y. Simpson M.D. Professor of Midwifery in the University of Edinburgh; with remarks collated from notes taken by George Mackay M.D. during the Winter Session 1850-1', p. 4. [LHB GD $1 / 1 / 4$ A \& B].

${ }^{30}$ Mackay, op. cit., note 29 above; 'Lectures on midwifery and the diseases of women given by J. Y.
Simpson M.D., Professor of Midwifery in the University of Edinburgh and taken down by George Dickson M.D., 1862-3' (Edinburgh University Special Collections, Gen.851); J Watt Black (ed.) Selected obstetrical and gynaecological works of Sir James $Y$. Simpson, Bart., Edinburgh, Adam and Charles Black, 1871. 
more radical works on the subject. Whilst direct evidence of his private practice is not immediately forthcoming, evidence of his charitable obstetric role is: prior to James Hamilton's death he had been associated with EGLIH, and from 1844 until his death he was one of the Ordinary Medical Officers of the ERMH.

In his lectures on midwifery, Simpson closely linked the management of delivery with the classification of the labour that preceded it. ${ }^{31}$ Exactly as in the casebooks' headings, Simpson taught his students to classify labour into "normal" (or "natural"), in which the foetus presented by the head, and labour was completed within twenty-four hours; "laborious", in which the presentation was again cephalic, but labour exceeded twenty-four hours; "preternatural", in which the presentation was not cephalic, but the breech or trunk; and "complex" or "anomalous", which resulted from complications on the part of either the mother or the child, including multiple pregnancy. Laborious labour was subdivided into "lingering" or "tedious", exceeding twenty-four hours but ending in a natural birth, and "instrumental". This in turn was classified, into deliveries potentially safe to mother and baby, destructive to the child, or "[i]njurious to the structures of the mother". ${ }^{32}$

Simpson made it clear that these classifications represented an amalgam of recent thinking on labour, and presented his own views as mainstream, coming somewhere between his mentor James Hamilton's opinion that a first stage in excess of twelve hours should be considered lingering, and Robert Collins' and Edward Rigby's views that labour could "extend with safety to the mother to 60 or 70 hours". 33 However, he qualified the early-nineteenth-century view of Thomas Denman, that only labour beyond twenty-four hours should be considered laborious, by making two exceptions, both shortening the time period: when the mother was exhausted before labour began, and when progress was "slight and lingering", 34 and he included protracted labour in his lectures on morbid parturition. Further, he incorporated in his lectures some of his own work in which he found a statistical relationship between the length of labour and maternal and infant mortality. ${ }^{35}$ However, in his published work he was more radical and forthright, stressing the debilitating effects on mother and child of a prolonged labour, and advocating the use of turning, both to hasten delivery and increase the chances of delivering a whole child through a suspected, rather than proven, contracted pelvis. ${ }^{36}$

None the less, possibly because he was training non-specialists, in his lectures Simpson declared that "[e]ven beyond 24 hours nothing is required but time and patience". ${ }^{37}$ His general advice to his students, in all the years from which lecture notes survive, was to trust nature as long as the head advanced, provided the mother's system was "not morbidly disturbed", and there was "no immediate danger to the infant". ${ }^{38}$ He cautioned that

\footnotetext{
${ }^{31}$ Unfortunately, this is the area in which Casebook recorders had most trouble. Some felt the classification extended to the mode of delivery (see footnote 46), and some produced hybrid classifications by ticking two boxes.

${ }^{32}$ Mackay, op. cit., note 29 above, p. 132.

${ }^{33}$ Ibid., p. 160. Collins was Master of the Rotunda, 1826-33; Rigby (1804-60), the physician at the Lying-in Hospital, Lambeth.

${ }^{34}$ Ibid., p. 158.

${ }^{35}$ Ibid., pp. 158, 160. See also James Y Simpson, On the duration of labour as a cause of mortality and
}

danger to the mother and infant; \&c. in reply to a letter of Dr Collins, Edinburgh, Sutherland and Knox, 1848, extracted from the Provincial Medical and Surgical Journal, 1 Nov. 1848.

${ }^{36}$ James Y Simpson, 'On turning as an alternative for craniotomy and the long forceps, in deformity of the brim of the pelvis, etc.', in Watt Black (ed.), op. cit., note 30 above, pp. 393-486, on pp. 409-19. 160

${ }^{37}$ Mackay, op. cit., note 29 above, pp. 158,

${ }^{38}$ Ibid., pp. 207, 209. 


\section{Alison Nuttall}

doctors with a town practice should not take forceps when first called to a maternity case, as there was "a great temptation to use them in a tedious labour which we should always if possible avoid". ${ }^{39}$ Indeed, his advice to the doctor, if remaining in the patient's house, was to "do what you can to amuse yourself", 40 as "[i]n natural labour our duty is purely expectant". ${ }^{41}$ Whilst, in the late 1840s, Simpson published innovative work on instrumental deliveries (and developed the necessary instruments: long forceps and an "airtractor" for vacuum extraction), this was not reflected in his lectures. ${ }^{42}$

However, Simpson recognized that there would also be a small number of protracted cases which did not progress to a normal delivery, "[w] here surgical aid [was] required, but safe in principle to mother $\&$ child", 43 Throughout his lectures, Simpson emphasized the seriousness of such a decision.

We always allow nature to try what she can do, and only interfere when she cannot bring the labour to a termination safe to the mother and child. It is not I repeat a question so much of how as when we should interfere instrumentally. I cannot too strongly impress upon you that no personal motives of comfort ... should influence us in using instruments to terminate the labour, we must consider solely the mother and child. Many criteria are required to judge the propriety or impropriety of instrumental interference. ${ }^{44}$

Among these he urged his listeners to consider the patient's previous obstetric history, the duration of the component stages of her labour, the situation of the head, the degree of dilatation and dilatability of the passages, the strength and effects of the contractions, the strength of the patient, and the state of the child. Such a range of criteria might be thought to offer scope to justify increasing use of forceps, and by Simpson's final lectures he was beginning to question, as he had already done in the medical press, the orthodox view that it was the intervention, rather than the delay, which caused the high mortality. None the less, he was aware of the limitations of contemporary instruments, and warned his 1862-3 class about the difficulties caused by slipping forceps. ${ }^{45}$ Although Simpson was more proactive in his published writing, to his students he advocated a policy of minimal intervention which changed little over time.

In both 1850 and 1870 the house surgeons and medical students at the ERMH were or had been predominantly Simpson's pupils. The hospital casebooks provide evidence of how they interpreted his teaching, and, occasionally, of his direct action. The two years can be considered together as in both the management of prolonged or difficult labour was similar, and the rate of intervention very low. In the combined Indoor and Outdoor practice in the two years together (1443 recorded cases), only 29 cases involved intervention at delivery, and of these, 19 were recorded as being delivered by forceps, 6 by podalic version, 2 by craniotomy, and one by post-mortem caesarean section. (Table 1 shows the complete breakdown of deliveries.)

\footnotetext{
${ }^{39}$ Ibid., p. 134.

${ }^{40}$ Ibid., p. 140: Simpson claimed "four-fifths of the papers he has published were written under these circumstances".

${ }^{41}$ Ibid., p. 6.

${ }^{42}$ James Y Simpson, 'On the mode of application of the long forceps', reprinted in Watt Black (ed.), op. cit., note 30 above, pp. 387-93; James Y Simpson, Two
}

notices of the obstetric air-tractor, Edinburgh, Sutherland and Knox, 1849; Myrtle Simpson, Simpson, the obstetrician, London, Victor Gollancz, 1972, pp. 176, 174.

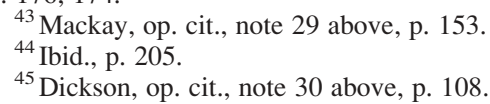


Changes in the Management of Difficult Childbirth, 1850-1890

Table 1

Number and Distribution of Deliveries at the ERMH in 1850 and 1870

\begin{tabular}{|c|c|c|c|c|}
\hline & \multicolumn{2}{|c|}{1850} & \multicolumn{2}{|c|}{1870} \\
\hline & Indoor & Outdoor & Indoor & Outdoor \\
\hline Total Cases (including abortions) & $* 291$ & 564 & 184 & 404 \\
\hline Total Labours Classified as Laborious & 14 & 12 & 4 & 18 \\
\hline Total Labours Classified as Preternatural or Complex & 14 & 31 & 9 & 14 \\
\hline Total Labours Unclassified or Unclear & 30 & 17 & 22 & 42 \\
\hline Total Normal Deliveries & 240 & 491 & 161 & 354 \\
\hline Total Labours Classified as Normal, Culminating in Spontaneous Delivery & 226 & 480 & 142 & 300 \\
\hline Associated Maternal Deaths & 1 & 0 & 0 & 0 \\
\hline Associated Stillbirths and Neo-Natal Deaths (in the care of the hospital) & 14 & 35 & 9 & 16 \\
\hline Outcome for Mother Unclear or Not Recorded & 1 & 6 & 11 & 76 \\
\hline Outcome for Mother Unclear or Not Recorded & 0 & 0 & 1 & 0 \\
\hline Outcome for Child Unclear or Not Recorded & 0 & 0 & 0 & 0 \\
\hline Total Labours Classified as Laborious, Culminating in Spontaneous Delivery & 10 & 6 & 2 & 13 \\
\hline Associated Maternal Deaths & 0 & 0 & 0 & 0 \\
\hline Associated Stillbirths and Neo-Natal Deaths (in the care of the hospital) & 2 & 3 & 0 & 1 \\
\hline Outcome for Mother Unclear or Not Recorded & 0 & 0 & 0 & 1 \\
\hline Outcome for Child Unclear or Not Recorded & 0 & 0 & 0 & 1 \\
\hline Total Labours Classified as Laborious, Culminating in Forceps Delivery & 3 & 6 & 2 & 2 \\
\hline Associated Maternal Deaths & 1 & 2 & 1 & 0 \\
\hline Associated Stillbirths and Neo-Natal Deaths (in the care of the hospital) & 2 & 4 & 1 & 0 \\
\hline Outcome for Mother Unclear or Not Recorded & 0 & 1 & 0 & 1 \\
\hline Associated Maternal Deaths & $\mathrm{nr}$ & 0 & 0 & 0 \\
\hline Associated Stillbirths and Neo-Natal Deaths (in the care of the hospital) & $\mathrm{nr}$ & 0 & 0 & 0 \\
\hline Outcome for Mother Unclear or Not Recorded & $\mathrm{nr}$ & 0 & 1 & 0 \\
\hline Outcome for Child Unclear or Not Recorded & $\mathrm{nr}$ & 0 & 1 & 0 \\
\hline Deliveries by Internal Podalic Version & 0 & 3 & 2 & 1 \\
\hline Associated Maternal Deaths & 0 & 0 & 0 & 0 \\
\hline Associated Stillbirths and Neo-Natal Deaths (in the care of the hospital) & 0 & 3 & 2 & 1 \\
\hline Outcome for Mother Unclear or Not Recorded & 0 & 0 & 0 & 0 \\
\hline Outcome for Child Unclear or Not Recorded & 0 & 0 & 0 & 0 \\
\hline Number of Other Instrumental Interventions at Delivery & 2 & 0 & 1 & 0 \\
\hline Associated Maternal Deaths & 1 & 0 & 0 & 0 \\
\hline Associated Stillbirths and Neo-Natal Deaths (in the care of the hospital) & 1 & 0 & 1 & 0 \\
\hline Outcome for Mother Unclear or Not Recorded & 0 & 0 & 0 & 0 \\
\hline Outcome for Child Unclear or Not Recorded & 0 & 0 & 0 & 0 \\
\hline
\end{tabular}

$\mathrm{nr}=$ not recorded

* 1850 Indoor total includes 21 patients entered only in Births Register, for whom there are therefore no records of delivery

**This is the case of Williamina Bayne, originally an Outdoor case, who was admitted in late labour, and delivered by forceps Indoors (thereby also appearing in the Indoor data relating to laborious labour), and died several days later.

Source: ERMH Indoor and Outdoor Casebooks and Births Registers for 1850, 1870. 


\section{Alison Nuttall}

The management of individual cases, typically in the hands of the house surgeon, and as recorded in the casebooks, supports the overall picture of minimal intervention presented by Simpson's lectures. In 1850, 12 Outdoor cases ( 2 per cent) were entered as laborious, although no times were recorded, and half of these delivered normally. All the mothers survived the unassisted prolonged labours to discharge, although three infants did not. Similarly, the 1870 Outdoor casebook shows that 18 out of 404 cases were considered laborious, of which 13 delivered spontaneously. ${ }^{46}$ No mothers died, but one stillbirth was recorded. Inside the hospital in 1850, 5 per cent of labours (14 cases) were described as laborious, presumably reflecting the higher proportion of primigravidae Indoors, as only two of these women were parous. Ten delivered themselves. Again, all the mothers survived, but there were two stillbirths. In 1870 four Indoor patients, all primigravid, were described as undergoing laborious labours, two of whom delivered naturally, with no recorded problems for mother or baby. Thus, in the majority of cases nature did prevail; experience of these ERMH cases would predispose doctors to trust that, "owing to the strength the pains had ... assumed", 47 their patients would deliver without intervention, and to expect their chief priority, the mother, if not always the infant, to recover from the birth.

However, in each year there was also a small number of protracted cases which did not progress to spontaneous delivery. Indoors in 1850, whilst none of the five women delivered by forceps laboured for more than twenty-four hours in total, three (two of whom were entered as "laborious"), lingered more than five hours in the second stage, their lack of progress late in labour and subsequent instrumental delivery indicating compliance by the hospital staff with Simpson's teaching. For example, Catharine McLairn was safely delivered of a live girl by forceps after a second stage of nine and a half hours. ${ }^{48}$ There was one exception: Helen McManus, who was delivered with forceps by Simpson himself immediately she reached full dilatation, after more than twenty-one hours in the first stage with a posterior position. ${ }^{49}$ Both mother and baby died, as did another infant. Maternal and infant mortality was consistently higher in instrumental cases than in those that eventually delivered spontaneously.

Outdoors in 1850, six ERMH patients were delivered by forceps. Labour stage times were not recorded routinely, but it was noted that two labours lasted twenty-nine and thirtyone hours respectively, whilst in a third "[h]ead impacted in outlet of pelvis for 7 or 8 hours, without making any advancement ... labour lasted about 36 hours". 50 All bar one were primigravid. As in the Indoor cases, the mortality and morbidity associated with instrumental deliveries was higher: two mothers died following forceps delivery, whilst a third was afflicted with "paralissis [sic] of bladder since application of forceps". 51 There were two stillbirths and two neo-natal deaths in the care of the hospital. Indoors and Out,

\footnotetext{
${ }^{46}$ Three of these cases were entered as "laborious", with "breech" written alongside, showing that the classifications were not always understood.

${ }^{47}$ LHSA, 1870 SOCB [LHB3/17/1], p. 38.

${ }^{48}$ LHSA, 1850 ICB [LHB3/16/A], case 2205 [115/ 2205/50si].
}

${ }^{49}$ LHSA, 1850 ICB [LHB3/16/A], case 1191 [026/ 1191/50fi].

${ }^{50}$ LHSA, 1850 OCB [LHB3/18/2], case 3009 [031/ 3009/50fo].

${ }^{51}$ LHSA, 1850 OCB [LHB3/18/2], case 3009 [031/ 3009/50fo]. 


\section{Changes in the Management of Difficult Childbirth, 1850-1890}

the need for forceps delivery was ascribed to pelvic deformity in three cases, and to protracted labour in eight.

In 1870 the mothers in all forceps cases were primigravidae. Three forceps deliveries were recorded Outdoors; in two cases, mother and child were discharged well, Ann Dogharty and her son surviving well a labour in which "[t]he os was 48 hours dilating", 52 for example. Most unusually, due to her home conditions the third case was admitted to the ERMH before delivery. ${ }^{53}$ She subsequently died. Indoors there were five forceps deliveries. Two mothers and babies survived; two infants and one mother died shortly after delivery, but the fate of two mothers and one child is unknown. Recourse to forceps was ascribed to pelvic disproportion in four cases, prolonged labour in two, whilst two were unexplained. The morbidity and mortality associated with instrumental delivery in both 1850 and 1870 suggest that it was rightly considered a serious operation: even when Simpson intervened to avoid a protracted second stage, the outcome was no better. However, whilst pelvic disproportion was blamed for delay in almost half the cases over the two years, no attempt was made to deliver such patients by turning.

Internal podalic version was employed on six occasions in the two years studied, but not to deliver women suspected of having contracted pelves, as Simpson had advocated. Three shoulder presentations were delivered Outdoors in this way in 1850, whilst it was also used to deliver quickly an Outdoor case of cord prolapse in 1870. All version cases were delivered by senior doctors, with the exception of that of Mrs McKinlay, who in 1850 had an arm presentation in her third pregnancy, when " $\mathrm{t}$ ] he child was turned by Dr. Harley in the presence of Dr. Simpson". ${ }^{54}$ However, Indoors in 1870 version was used to deliver two women who, in contrast to the primigravidae discussed above, were known, by their previous obstetric history, to have contracted pelves. Mrs Airey, an engineer's daughter, twenty-eight years old and in her fourth pregnancy, was "sent up from Penrith to be prematurely delivered in consequence of contracted pelvis". After sixteen days in the hospital, "Dr. Keiller dilated Os artificially turned and extracted", but failed to deliver a live baby. ${ }^{55}$ This delivery was also attended by Dr Bell and both house surgeons. Mrs Stewart, a native of the Canongate, aged twenty-six and also in her fourth pregnancy, but with an unknown history, was similarly delivered by a group that included James Simpson, Keiller, and Bell. No mother died as a result of delivery by version, but no child survived. Maternal morbidity is harder to assess: a fuller than usual record shows that Mrs Stewart stayed in the hospital for ten weeks afterwards, presumably recovering. ${ }^{56}$

The seriousness of the decision to intervene is underlined by the presence of other senior doctors. Although Simpson did not actually recommend consultation, the Hospital Rules directed that in "cases of danger the Ordinary Medical Officer shall ... request the attendance of the other members of the Medical Board". ${ }^{57}$ The records for both years

\footnotetext{
${ }^{52}$ LHSA, 1870 OCB [LHB3/18/2], case 594 [060/ 594/70fo].

53 " $[\mathrm{T}]$ he room in which she was, did not seem so well ventilated as to enable one to give a prognosis at all favourable". (LHSA, 1870 SOCB [LHB3/17/1], p. 39-40).

${ }^{54}$ LHSA, 1850 OCB [LHB3/18/2], case 3407 [216/3407/50so]. George Harley was then a house
}

surgeon: presumably he was being instructed by Simpson.

${ }^{55}$ LHSA, 1870 ICB [LHB3/16/A], case 1615 [031/ 1615/70fi].

${ }^{56}$ LHSA, 1870 ICB [LHB3/16/A], case 1599 [015/ 1599/70fi].

${ }^{57}$ Rules and Bye-Laws, op. cit., note 10 above, "Ordinary Medical Officers", Rule 4. 


\section{Alison Nuttall}

show forceps delivery followed consultation between seniors in five cases, in addition to the two Indoor version cases above. Consultation appears to have been a widespread practice,${ }^{58}$ although the emphasis on it in the ERMH Rules could indicate the Directors' fear that doctors would abuse their patients by over-treatment or experiment. Whether or not formal consultation took place on every occasion, all the women whose cases have been described were delivered in the presence of a senior doctor, fifteen by him, and five by the house surgeon under supervision.

None the less, it could be suggested that the low level of intervention at the ERMH was the result of a lack of concern by doctors attending charity cases. However, both house surgeons and students were practising on the poor the care they were being trained to offer private patients, under strict rules of conduct laid down by the hospital. ${ }^{59}$ It can also be suggested that to use hospital-based care was in fact a sound strategy for the poor to adopt, as in the event of complications they had free access to the senior doctors associated with it, whilst they were sufficiently un-intimidated by its junior staff to continue their previous birth practices. ${ }^{60}$ Such a strategy seems justified at the ERMH, as Simpson was the most frequently recorded senior doctor at difficult deliveries in 1850, whilst in 1870 that distinction fell to Alexander Keiller, Lecturer in Midwifery at the College of Surgeons. Nevertheless, it should be noted that, until the mid-1870s, less-distinguished general practitioners also served the hospital as ordinary physicians.

Moreover, evidence of deliveries from elsewhere in Britain at the same period also shows low levels of intervention, suggesting this was not a peculiarly Edinburgh practice. Irvine Loudon has written in general terms of the excessively conservative management of labour at this period, and has also analysed the writings of eleven general practitioners who published the results of their practice between 1831 and 1876. He notes that their use of forceps ranged from 0.1 per cent to 2 per cent. ${ }^{61}$ Minimal use of forceps has also been noted at the deliveries of upper-middle-class women; ${ }^{62}$ as doctors were aware, patients and their relations were largely resistant to their use. ${ }^{63}$

When the actual treatment of prolonged labour at the ERMH in 1850 and 1870 is compared with that advocated by Simpson in his lectures and writing, it can be seen that it tended to be more conservative. Typically, intervention occurred only after an extremely lengthy second stage, when all progress had ceased, even when the labour as a whole did not exceed twenty-four hours. Version was used in accordance with long practice, and not as an alternative mode of delivery when the cause of delay in descent of the head was uncertain. However, the low maternal mortality and morbidity

\footnotetext{
${ }^{58}$ See the comments of Dr Lombe Atthill (later Master of the Rotunda): Br. med. J., 1873, ii: 261; and also of Thomas More Madden, 'On certain improvements in the construction and use of long and short midwifery forceps', Br. med. J., 1874, i: 829-32, p. 831 .

${ }^{59}$ Rules and Bye-Laws, op. cit., note 10 above, "House Surgeons", Rule 3; "Pupils", Rules 4-8.

${ }^{60}$ This point was made first in Leavitt, op. cit., note 5 above, pp. 84-5, and re-iterated in Quiroga, op. cit., note 6 above, pp. 41-2. Nancy Dye's work on the New York Midwifery Dispensary provides a vivid
}

illustration of this in Dye, op. cit., note 6 above, especially pp. 553-6.

${ }^{61}$ Irvine Loudon, Death in Childbirth, Oxford,

Clarendon Press, 1992, p. 183, Table 12.1, p.187.

${ }^{62}$ Jalland, op. cit., note 5 above, p.142.

${ }^{63}$ In $1869 \mathrm{Mr}$ Charles Amsden addressed the Edinburgh Obstetrical Society on his modification of the fillet, which he presented as an alternative to forceps, claiming that these "present a very formidable appearance ... frequently objected to strongly by both patients and friends," (Edinburgh med. J., 1869, 15:

81-2,p. 82). See also Leavitt, op. cit., note 5 above, p. 48. 
associated with the majority of laborious labours delivered spontaneously, suggest this was not unsafe practice, despite Simpson's work to the contrary. Further, it implies a positive mindset towards natural labour in its medical attendants, although their primary focus was the survival of the mother.

None the less, the circumstances of the fatal 1870 Indoor case illustrate the limitations of this approach. Despite the evident concern and care of all ERMH staff involved in her treatment (and ultimately these included the medical student originally sent to attend her, both house surgeons, and two ordinary physicians), Williamina Bayne, a twenty-year-old primigravida, laboured for almost fifty-nine hours, including eleven in the second stage, during which minimal progress was made. Following six-and-a-half hours of consultation and procrastination by senior staff, she was ultimately delivered by long forceps, dying, apparently from infection, five days later. ${ }^{64}$ However, the very detailed casebook account of this case, written by W John Kennedy, one of the house surgeons, contains within it criticism both of the hospital rules regarding intervention, and of the non-intervention strategy itself, thereby suggesting that the existing management of prolonged labour in the hospital had become open to question. ${ }^{65}$ Further, the growing amount of writing in the British medical press on the subject of intervention at delivery, examined in the next section, suggests both that any previous consensus was disappearing, and that there was increasing tension between those who advocated earlier intervention, and those who still trusted to nature.

\section{Changing Attitudes to Intervention at Delivery after 1870}

By the late 1860s, arguments were beginning to be made in the medical press in favour of both earlier intervention, and increasing use of instruments. Material presented to the Annual Meetings of the British Medical Association, and contributions to the British Medical Journal and the Lancet at this period, indicate the range of contemporary medical thought on the management of prolonged labour, and thus the degree to which the monolithic practice Simpson had presented to his students in 1850 had broken down.

From 1860, correspondents to the Lancet in particular had presented to readers analyses of their midwifery practice, similar to Simpson's initial analysis of the ERMH. At first these studies indicated a low rate of both interventions at delivery, and of maternal deaths. ${ }^{66}$ However, by the early 1870 s, there was considerable correspondence in favour of earlier intervention, taking up Simpson's idea that this would save the lives of both mothers and children. In 1870 itself, a review was published in the British Medical Journal of Robert Barnes's Lectures on obstetric operations ... a guide to the management of difficult labour. The anonymous reviewer commented that "we trust that Dr Barnes's

\footnotetext{
${ }^{64}$ LHSA, 1870 SOCB [LHB3/17/1], pp. 36-44. She was one of only two patients to die in the care of the hospital in 1870, out of a total of 588 .

${ }^{65}$ Kennedy felt "the best course ... would have been to turn the child before allowing the liquor amnii to escape" (Simpson's apparent method of choice). However, "the House Surgeon ... is not allowed to perform an obstetric operation on his own
}

\author{
responsibility unless there is immediate danger to \\ mother or child", and he therefore trusted that \\ "owing to the strength the pains had now \\ assumed, the head might be enabled to enter \\ the brim". (LHSA, 1870 SOCB [LHB3/17/1], \\ p. 38.) \\ ${ }^{66}$ See, for example, that of Dr Cross of \\ Scarborough, Lancet, 1860, ii: 274.
}




\section{Alison Nuttall}

exposition of the forceps will lead not only to its more dexterous, but also its more timely, application". ${ }^{67}$ In 1873, Dr James More, a former pupil of Simpson's and a general practitioner in Rothwell, Northamptonshire, wrote that he was familiar with Simpson's advice not to take forceps, and felt he had been "taught to avoid the use of instruments so long as there was any progress". However, he had been persuaded by his admiration for Simpson's paper demonstrating an association between longer labour and increased maternal and infant death, to examine his own practice. In the early period, he had carried out few forceps deliveries, but had gradually recognized (he claimed) that long labour led to a long recovery period which working women, typically back at their housework on the third postnatal day, could not afford. This apparent sympathy led him to advocate the more frequent use of forceps which he believed to be to the benefit of both parties: "I do not scruple to use the means at my command of relieving the woman from travail and myself from work". 68

In the same year, the exceptionally detailed report of the British Medical Association Annual Meeting shows that, while no speaker matched Dr More's enthusiasm, almost all favoured increasing intervention. Dr Steele supported Simpson's findings, declaring that "[s]tatistics had abundantly shown that the maternal and foetal death-rates were diminished in direct ratio to the frequency with which the forceps were used"; 99 Dr More Madden took the debate slightly further: he believed medical education had failed to keep up with changes in obstetric thinking. ${ }^{70}$ However, Dr Wiltshire "objected to the use of long forceps in ordinary cases", ${ }^{71}$ and Dr Atthill of Dublin felt forceps deliveries were now too common in that city.

The medical press continued to include arguments from both sides. ${ }^{72}$ In 1876 , William O Priestly, the President of the London Obstetrical Society, claimed in his retiring address that in "ordinary midwifery practice ... a sort of revolution may be said to have taken place in the views entertained by medical practitioners on this subject [forceps deliveries]", 73 although intervention continued to be a hotly debated topic at Society meetings for several years. $^{74}$

However, whilst writings in the medical press indicated changing attitudes to intervention in prolonged labour among practitioners, the need for more effective technology was met only with the development of axis-traction forceps by Stéphane Tarnier (surgeon in chief at the Maternité in Paris) in 1877. These addressed the major difficulties associated with using forceps from the doctor's point of view: they did not slip in use, a hazard described by James Simpson in 1863; they were said to be easier to apply, and the innovative axis-traction handle enabled the operator always to pull in the axis of the

\footnotetext{
${ }^{67} \mathrm{Br}$. med. J., 1870 , i: $312-14$, p. 313.

${ }^{68}$ James More MD, 'On the use of the forceps in midwifery', Lancet, 1873, ii: 590-1, p. 591.

${ }^{69} \mathrm{Br}$. med. J., 1873, ii: 261.

${ }^{70}$ Ibid.

${ }^{71}$ Ibid.

${ }^{72}$ See, for example, the presentations made by $\mathrm{Dr}$ Edward Rigden to the East Kent District meeting of the BMA (Br.med.J., 1874, i: 787), and by Dr Cooper Rose
}

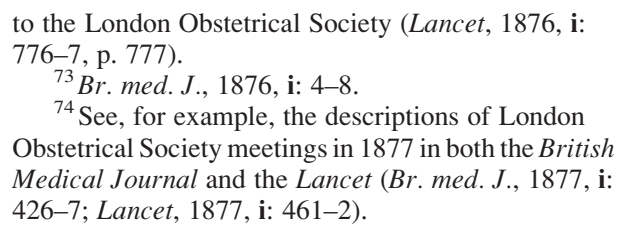

${ }^{74} \mathrm{See}$, for example, the descriptions of London Obstetrical Society meetings in 1877 in both the British Medical Journal and the Lancet (Br. med. J., 1877, i: 426-7; Lancet, 1877, i: 461-2). 
pelvis, whatever the position of the head, thus much reducing the amount of force required, and the potential for tissue damage. ${ }^{75}$

These shifting attitudes to intervention were largely articulated within the Edinburgh medical world by Alexander Simpson, nephew to Sir James and his successor as Professor of Midwifery. ${ }^{76}$ Their development can be traced in surviving lecture-notes from his annual courses of lectures. In 1873-4, he devoted two lectures to the mechanism of natural labour, and three to its management and the care of the patient, and, like his uncle, detailed appropriate clothing for both mother and delivery bed. Again, he did not recommend taking forceps when first called, although he acknowledged that some doctors did. However, unlike his uncle, he also included precise instructions for a variety of interventions, and believed version to be "more dangerous than forceps". ${ }^{77}$ From the following academic year, part of his Saturday class was devoted to 'Practical instruction in the use of obstetrical and gynaecological instruments and appliances'. ${ }^{78}$ In addition, he advised his students always to be prepared for a further stage of treatment; for example, for destruction if version failed. ${ }^{79}$ His $1890-1$ lecture notes recorded less on the management of normal labour, although forceps still did not appear in the routine armamentarium to be taken to cases. ${ }^{80}$ Alexander Simpson's advice on instrumental labour remained to "[ $\mathrm{t}$ ]rust to nature provided the uterine contr[action]s still advance the head". Should forceps prove necessary, Simpson enthusiastically recommended Tarnier's invention: “[a]xis traction forceps are best. They are somewhat complicated but this is no real disadvantage". ${ }^{81}$ He gave detailed instructions on their use. By 1897-8, forceps appeared as a routine part of his list of standard equipment to be taken to a delivery, whilst the care described was strictly medical, as "there should always be some reliable female assistant present". ${ }^{2}$ Thus Alexander Simpson's lectures, with their emphasis on a systematic approach to the management of

\footnotetext{
${ }^{75}$ P M Dunn, 'Stéphane Tarnier (1828-1897), the architect of perinatology in France', Arch. Dis. Child Fetal Neonatal Ed., 2002, 86: F137-F139.

${ }^{76}$ Sir Alexander Russell Simpson (1835-1915), Professor of Midwifery and the Diseases of Women and Children, University of Edinburgh, 1870-1906.

77 'Lectures on midwifery and the diseases of women given by Alexander R. Simpson, 1873-4', taken down by an unknown student, lecture 77, 3 Mar. 1874, p. 278 (Edinburgh University Special Collections, Dc10.35 ${ }^{1-2}$ ).

${ }^{78}$ Edinburgh University Calendar for 1874-5, Edinburgh, James Thin Booksellers and Publishers, 1874, pp. 99-100. Analysis of the ERMH casebooks suggests that in 1850 and 1870 efforts were made to show interventions and the use of instruments to the house surgeons (who paid larger fees) whenever a suitable opportunity presented (see, for example, footnote 54). However, in all years studied, medical students saw instruments in actual use only if they were necessary to deliver the woman to whom the student had previously been allocated.

79 'Lectures on midwifery', op. cit., note 77 above, p. 278
}

\footnotetext{
${ }^{80}$ However, it should be noted that his successor as professor, John Halliday Croom, was recommending to his students at the Extra-Mural School in 1887-8 that they should take forceps routinely. (LHSA, 'Lectures on midwifery and the diseases of women given by John Halliday Croom, 1887-8', taken down by Frederick W Mann, lecture undated, p. 137 [LHB G\&D 1/1/5 $\mathrm{A} \& \mathrm{~B}])$.

${ }^{81}$ 'Lectures on midwifery and the diseases of women given by Alexander R. Simpson, 1890-1', taken down by an unknown student, lecture of 11 Feb. 1891 (no pagination) (Edinburgh University Special Collections, Dk 4.5). Whilst Simpson praised axis-traction forceps, and even produced his own variation, the type of forceps used in 1890 is mentioned only once, when, at Mrs Morrison's delivery in November 1890, the "[a]xis-traction forceps [were] applied by Dr. Duncan but they failed to move head". (LHSA, 1890 OCB [LHB3/18/5], case 7 (Prof. Simpson's second quarter) [214/7ss/90so]).

${ }^{82}$ David Jones Hughes, 'Lectures on midwifery and the diseases of women given by Alexander R. Simpson, 1897-8', lecture of 13 Jan. 1898 (no pagination) (Edinburgh University Special Collections, MS2641-MS2642).
} 


\section{Alison Nuttall}

prolonged or obstructed labour, apparently indicate a fundamental change in medical attitude, in which a recommended protocol replaced individually prescribed treatment.

\section{The Management of Prolonged Labour at the ERMH, 1890}

The hospital data from 1890 demonstrate how the changes in treatment resulting from more interventionist theories of the management of prolonged labour were interpreted in the hospital at which Alexander Simpson was Ordinary Physician. Hospital staff delivered 960 patients in that year, of whom 76 were delivered by forceps, 8 by podalic version, 2 by Prêvot's operation, and one by post-mortem caesarean section. (Table 2 shows the full data.)

Indoors in 1890, 48 labours were entered as "laborious", of which seven delivered spontaneously and 39 were delivered by forceps. The two remaining laborious cases were both delivered by podalic version for severely contracted pelvis, one being a repeat patient, a victim of childhood rickets. ${ }^{83}$ All bar one of those who delivered normally were primigravid, and all laboured for more than twenty-four hours, but presumably they continued to progress. All the mothers survived, but there were two stillbirths. More than half of the 40 delivered by forceps, again mostly primigravid, laboured for more than twenty-four hours, whilst two-thirds were in the second stage for more than three hours. There was one stillbirth, but all the mothers survived. In addition, three women whose labours were considered normal in duration were delivered by forceps: all had second stages in excess of two hours. The Indoor forceps cases show that whilst there was a big increase in intervention, typically justified on the grounds of delay or uterine inertia, nature was none the less given a fair trial. They also show that the maternal and infant mortality associated with forceps cases in 1850 and 1870 had largely disappeared. However, the Indoor casebooks show a further major change in intervention strategy, in that forceps deliveries had become part of the house surgeons' skills, and ceased to require the presence of a senior doctor. Only one such delivery was not carried out by a house surgeon.

Evidence from the Outdoor casebook is similar. Although labour stage timings were not officially recorded, 24 cases were described as laborious, of which only two delivered without assistance, and one was a breech presentation. In contrast to 1850 and 1870, the remaining 21 were almost equally divided between the primigravid and the parous, including six who were having their fifth or subsequent baby. There were no maternal deaths among them, although there were two stillbirths. Only two patients were described as having a contracted pelvis: for the great majority, the reasons for intervention were delay or inertia. In addition, five women whose labours were considered of normal length were delivered by forceps; this group included Mrs Donoghue, a 22-year-old having her third child, in whose case "Dr. Gillespie applied forceps to head at brim for slightly contracted brim, head making no progress for 8 hours". ${ }^{84}$ Again there were no associated deaths, and there was no evidence of morbidity. All the mothers did well, but one baby was stillborn. Three women were delivered by version, in two cases because attempts at forceps delivery

\footnotetext{
${ }^{83}$ LHSA, 1890 ICB [LHB3/16/2], case 64 (Dr
} Berry Hart's quarter) [064/38bh/90fi].

\footnotetext{
${ }^{84}$ LHSA, 1890 OCB [LHB3/18/5], case 70 (Dr Underhill's quarter) [291/70u/90fo].
} 
Table 2

Number and Distribution of Deliveries at the ERMH in 1890

\begin{tabular}{|c|c|c|}
\hline & \multicolumn{2}{|c|}{1890} \\
\hline & Indoor & Outdoor \\
\hline Total Cases (including abortions) & 294 & 666 \\
\hline Total Labours Classified as Laborious & 48 & $* * 24$ \\
\hline Total Labours Classified as Preternatural or Complex & 30 & 46 \\
\hline Total Labours Unclassified or Unclear & 5 & 3 \\
\hline Total Normal Deliveries & 204 & 563 \\
\hline Total Labours Classified as Normal, Culminating in Spontaneous Delivery & 195 & 557 \\
\hline Associated Maternal Deaths & 1 & 0 \\
\hline Associated Stillbirths and Neo-Natal Deaths (in the care of the hospital) & 10 & 27 \\
\hline Outcome for Mother Unclear or Not Recorded & 2 & 1 \\
\hline Outcome for Mother Unclear or Not Recorded & 0 & 0 \\
\hline Outcome for Child Unclear or Not Recorded & 0 & 0 \\
\hline Total Labours Classified as Laborious, Culminating in Spontaneous Delivery & 7 & 2 \\
\hline Associated Maternal Deaths & 0 & 0 \\
\hline Associated Stillbirths and Neo-Natal Deaths (in the care of the hospital) & 2 & 0 \\
\hline Outcome for Mother Unclear or Not Recorded & 0 & 0 \\
\hline Outcome for Child Unclear or Not Recorded & 0 & 0 \\
\hline Total Labours Classified as Laborious, Culminating in Forceps Delivery & 39 & 21 \\
\hline Associated Maternal Deaths & 0 & 0 \\
\hline Associated Stillbirths and Neo-Natal Deaths (in the care of the hospital) & 2 & 2 \\
\hline Outcome for Mother Unclear or Not Recorded & 0 & 0 \\
\hline Associated Maternal Deaths & 2 & 0 \\
\hline Associated Stillbirths and Neo-Natal Deaths (in the care of the hospital) & 6 & 0 \\
\hline Outcome for Mother Unclear or Not Recorded & 0 & 0 \\
\hline Outcome for Child Unclear or Not Recorded & 0 & 0 \\
\hline Deliveries by Internal Podalic Version & 5 & 3 \\
\hline Associated Maternal Deaths & 0 & 1 \\
\hline Associated Stillbirths and Neo-Natal Deaths (in the care of the hospital) & 3 & 2 \\
\hline Outcome for Mother Unclear or Not Recorded & 0 & 0 \\
\hline Outcome for Child Unclear or Not Recorded & 0 & 0 \\
\hline Number of Other Instrumental Interventions at Delivery & 1 & 2 \\
\hline Associated Maternal Deaths & 0 & 2 \\
\hline Associated Stillbirths and Neo-Natal Deaths (in the care of the hospital) & 1 & 2 \\
\hline Outcome for Mother Unclear or Not Recorded & $* 1$ & 0 \\
\hline Outcome for Child Unclear or Not Recorded & 0 & 0 \\
\hline
\end{tabular}

*Health on discharge not recorded, but described as "making good recovery" and several return visits to the ERMH (ERMH Special \& Ordinary Casebook, pp. 80-1)

** This includes one incorrectly classified breech presentation, excluded from the data below.

Source: ERMH Indoor and Outdoor Casebooks and Births Registers for 1890

failed. Again, the majority of forceps deliveries were carried out by the house surgeon. However, there were three exceptions, all known to have contracted pelves, who were delivered by the assistant physician, his presence in each case indicating the preparedness to proceed to the next stage described by Alexander Simpson. Most notable among them 


\section{Alison Nuttall}

for her successful delivery in the face of a poor previous history, was Mrs Cassidy, a 21-year-old gravida 3.

Although for the inpatients the function of the hospital had changed very little, still being seen primarily as a shelter, the management of Mrs Cassidy's case shows how much more medically structured the hospital's treatment of its Outdoor patients had become by 1890. It is not clear whether her previous obstetric history of "two dead born children previously, with a history of protracted labours", 85 was known prior to the day of her delivery, as the casebooks do not reveal whether attendance was booked in advance by the patient. ${ }^{86}$ By whatever means Mrs Cassidy summoned help, she was first attended by a team of two medical students and two pupil midwifery nurses. This was typical for any Outdoor delivery. Medical students attending the ERMH in 1890 were the senior attendants at 526 of the 666 Outdoor deliveries: in approximately half the cases they attended they had a student partner, and in four-fifths of their cases they were also accompanied by one or, more often, two nurses. This contrasts with attendance in 1850 and 1870, when Outdoor patients were typically attended by a single medical student or pupil midwifery nurse. Textual evidence describes the 1890 nurses as providing care for the mother until recovery, presumably associated with the introduction of routine antisepsis procedures in the hospital in 1881 which precipitated the appointment of the staff nurse. ${ }^{87}$ The professionalization of care in labour and post-delivery that this implies again contrasts with even twenty years earlier, when patients depended on their family for care and support in labour and the puerperium, and the hospital made little effort to provide this. $^{88}$

As in difficult cases in 1850 and 1870, both house surgeons were listed as present at Mrs Cassidy's delivery, but they appear to have taken no active role. However, the house surgeons of 1890 were more medically mature than were those of 1870 . Whilst James Lawson-Williams registered with the General Medical Council only in 1890, Edward Farr Armour, the other house surgeon at the delivery, had been registered since 1888, and had previous experience as a house physician in the Royal Infirmary. This contrasts with the careers of house surgeons in 1850 and 1870, who were newly qualified or senior students when they took up their posts at the ERMH. ${ }^{89}$ However, it is the presence in Mrs Cassidy's house, and the prompt action of Robert Milne Murray, assistant physician to the ERMH, medical officer of the Western Dispensary, secretary of the Edinburgh Obstetrical Society and Lecturer in the Diseases of Women and Children in the Edinburgh School of Medicine, which indicates how much more pro-active the care given by the ERMH had become. A man already making a good career in the specialty of obstetrics, he did not "trust [in] ... the strength that the pains had assumed", the strategy found wanting in the Bayne case of

\footnotetext{
${ }^{85}$ LHSA, 1890 OCB [LHB3/18/5], case 52 (Dr Halliday Croom's quarter) [106/52hc/90so].

${ }^{86}$ Although see LHSA, 1890 SOCB [LHB3/17/6], p. 73.

${ }^{87}$ See, for example, LHSA, 1890 SOCB [LHB3/17/

6], p. 61; ARERMH [LHB3/7/48], 1893, p. 9.

${ }^{88}$ Whilst sick Indoor patients were described as being nursed by 1870 , in 1862 the Directors responded to the suggestion that they should hire a nurse to assist
}

the matron by stating that the antenatal patients looked after the postnatal patients. (DMERMH [LHB3/1/2], 6 Dec. 1862).

${ }^{89}$ For example, W John Kennedy passed his finals in July 1870 and took up his post in August; in 1850 George Harley took his final examinations whilst in post; the 1871 census describes Joseph Vincente Forfar as both house surgeon and medical student. 
twenty years before, but "applied forceps \& delivered child alive on this occasion". 90 His presence also shows a pre-prepared scheme for dealing with predicted problems, reflecting Alexander Simpson's emphasis on a precautionary approach to treatment: had version proved necessary, there would have been no delay caused by sending for him.

\section{Conclusion}

The shift from a reliance on nature to intervention in labour should not be over-emphasized. The hospital data clearly show that forceps were not being used excessively in 1890 and that its patients' labours were not the subject of unnecessary intervention when they stood a high chance of delivering naturally. None the less, the 1890 data show that a change had occurred in the proportion of interventions at deliveries carried out by hospital staff, and that this, and the improvement in outcomes for both mother and child, conformed to the interventionist theories that gained dominance in the obstetric profession during the late 1870s, as has been described in general terms by Loudon. ${ }^{91}$ At the ERMH, the change preceded any variation in the type of patients admitted, and therefore indicates a genuine alteration in their approach to birth by increasingly specialist obstetricians, and an indication that the hospital was adopting a more dominant medical role.

Further, the casebook material gives the impression that the trend was unopposed by patients and their families. They now accepted the use of forceps without particular fear or anxiety (a lessening of suspicion also noted at much the same period among the British upper middle class), although they continued to be independent regarding other aspects of their care, most notably admission. ${ }^{92}$ Moreover, this shift is clearly reflected in the apparent loss of status of forceps deliveries as a result of their increased use. No longer was their application preceded by consultation between senior doctors, who themselves carried out the delivery: instead it was one of the many treatments delegated to an unsupervised house surgeon. By reducing the delay that formerly resulted from calling for a senior doctor to attend, this may of itself have increased the number of instrumental deliveries and reduced associated mortality.

There was a paradox at the heart of James Simpson's work: on the one hand he confidently assured his students that usually time sufficed, whilst on the other, his own statistical analysis suggested that earlier intervention could save lives. The changes in the management of prolonged labour which were made in the last quarter of the nineteenth century were part of a fundamental alteration in the medical approach to childbirth. Greater concern for the child combined with difficulty in predicting outcomes encouraged doctors to mistrust nature, to consider labour normal only in retrospect, and to be prepared for increasingly serious action until delivery was achieved. Further, the changed management demanded greater obstetric skill from doctors, although it also offered greater professional opportunities. It altered, too, the relationship between the labouring mother and her attendant midwife or nurse, who now had to judge her progress in labour as well as providing comfort, and who had further duties of care to both the unborn child and the doctor involved.

${ }^{90}$ LHSA, 1890 OCB [LHB3/18/5], case 52 (Dr Halliday Croom's quarter) [106/52hc/90so].

\footnotetext{
${ }^{91}$ Loudon, op. cit., note 61 above, p.184.

${ }^{92}$ Jalland, op. cit., note 5 above, p.142.
} 


\section{Alison Nuttall}

Similarly, changes in the management of childbirth made greater demands of the hospital. Although in 1890 it remained unchanged in many ways, and this paper rests upon the argument that Indoor patients continued to see it as a source of social rather than medical care, both the medical support given to difficult Outdoor cases and the routine nursing care given to all patients during delivery and the puerperium, suggest a more disciplined and structured organization than existed in 1870, and one that contributed to the success of a more interventionist approach to labour. None the less, it still perceived its major role as providing effective care in domiciliary childbirth: even the publicity to raise funds for Indoor accommodation for married patients stressed the good quality of Outdoor care provided.

Finally, this article demonstrates the value of casebook evidence in illuminating historical debates about the management of childbirth in the nineteenth century. Whilst such casebooks are the product of single institutions treating a very small proportion of the parturient population, the themes that they contain are applicable to childbirth in Britain in general. They draw out the reality of changes in treatment and obstetric practice, tempering the extremism of the more theoretical writings of the medical press; they emphasize the role of patient tolerance in changes in medical treatment, even among the poor, and, above all, they illuminate the changing functions and skills of the staff involved, showing the influence of increasing professionalism on maternity care. 